\title{
Yol Geometrik Standartlarının Karayolu İşletme Maliyetleri Üzerindeki Etkisinin İncelenmesi ${ }^{1}$
}

\author{
Soner CANVER ${ }^{*(D)}$, Halit ÖZEN ${ }^{2}$ (D) Abdulsamet SARAÇOĞLU $^{3}$ (D), \\ Abdullah MALTAŞ ${ }^{4}$ \\ ${ }^{1}$ Harita Mühendisi, Yıldız Teknik University, Faculty of Civil Engineering, Department of Civil Engineering, \\ İstanbul, Turkey \\ ${ }^{2}$ Assoc. Prof. Dr., Yıldız Teknik University, Faculty of Civil Engineering, Department of Civil Engineering, \\ İstanbul, Turkey \\ ${ }^{3}$ Research Asst., Yıldız Teknik University, Faculty of Civil Engineering, Department of Civil Engineering, \\ İstanbul, Turkey \\ ${ }^{4}$ Research Asst., Yıldız Teknik University, Faculty of Civil Engineering, Department of Civil Engineering, \\ İstanbul, Turkey
}

Geliş Tarihi/Received: 05.01.2019

Kabul Tarihi/Accepted: 04.03.2020
Doi: doi.org/10.31200/makuubd.508625

Araştırma Makalesi/Research Article

\section{ÖZET}

Ulaştırmanın üç temel bileşeni; insan, taşıt ve altyapı şeklindedir. Ulaştırma sisteminin işletimi sırasında, bu bileşenlerin hem kendileri hem de birbirleri ile olan ilişkilerinde ortaya çıkan sorunlar "maliyet" olarak tanımlanmaktadır. Ulaştırma sisteminin planlanması aşamasında, işletim sırasında karşılaşılacak maliyetlerin tanımlanması ve analiz edilmesi gerekmektedir. $\mathrm{Bu}$ bağlamda, ülkemizde yoğun olarak kullanılan karayolu ulaşımı için de işletme maliyetlerinin ayrı ayrı belirlenmesi ve bunların etkilerinin değerlendirilmesi büyük önem arz etmektedir. Karayolu ulaşımında işletme maliyetleri; taşıt işletme maliyeti, emisyon maliyeti, zaman kaybı maliyeti ve yol güvenliği maliyeti olmak üzere 4 ana başlıkta toplanmaktadır. Bunlar arasında taşıt işletme maliyeti, en büyük maliyet oranına sahiptir. Yakıt tüketimi, bakım-onarım gibi doğrudan kullanıcıya yansıyan bu maliyetleri azaltmada yolun karakteristik özellikleri büyük önem arz etmektedir.

\footnotetext{
${ }^{1} \mathrm{Bu}$ çalışma “'II. International Scientific and Vocational Studies Congress (BILMES 2018)" kongresinde bildiri sunulmuştur.

* Sorumlu yazar/Corresponding author

E-mail/e-ileti: sonercanver@gmail.com
} 
Bu çalışmada, karayolu işletme maliyetlerinin neler olduğu ve maliyet hesaplamalarına ilişkin yöntemler detaylı olarak incelenmiştir. Dünya Bankası tarafından yol proje maliyetlerinin hesaplanması için geliştirilen HDM-4 yazılımı kullanılarak, yazılım parametrelerindeki değişimin işletme maliyetine etkisi analiz edilmiştir. Çalışma kapsamında, parametre değişiminin etkisi projelendirilen bir yol güzergahı için belirlenmiştir. Sonuç olarak; taşıt işletme, çevresel etkiler ve yol geometrik özelliklerine ilişkin kullanılan parametrelerin yol işletme maliyetine olan etkisi ortaya konulmuştur.

Anahtar kelimeler: Karayolu İşletme Maliyetleri, Yol Geometrik Standartları, HDM-4 Yazilımı.

\title{
Investigation of the Effects of Road Geometric Standards on Highway Operating Costs
}

\begin{abstract}
The three main components of transportation are human, vehicle, and infrastructure. During the operation of the transportation system, the problems of these components both in themselves and in their relations with each other are defined as "cost". In the planning stage of the transportation system, the costs to be encountered during operation must be identified and analyzed. In this context, it is very important to determine the operating costs separately and to evaluate their effects on the highway transportation that is heavily used in Turkey. Operating costs in the highway transportation are divided into four main categories; vehicle operation cost, emission cost, time loss cost, and road safety cost. Among them, the vehicle operation cost has the greatest cost value. Characteristic features of the highway are of great importance to reduce these costs that directly affect the user, such as fuel consumption, maintenance, and repair.
\end{abstract}

In this study, highway operating costs and methods for calculating costs sre examined in detail. The effect of the change in software parameters on the project cost is analyzed by using the HDM-4 software developed by the World Bank to calculate highway operating costs. In this study, the effect of the change in software parameters is determined for a specific highway. Consequently, effects of the parameters that are used for vehicle operation, environmental effects and the geometric properties of the highway are exposed.

Keywords: Highway Operation Costs, Highway Geometrical Standards, HDM-4 Software. 
Canver, S., Özen, H., Saraçoğlu, A. \& Maltaş, A.

\section{GİRİ̧̧}

Ulaştırmanın üç temel bileşenini taşıt, altyapı ve insan oluşturmaktadır. Bu bileşenlerin kendisi ve birbirleri ile olan ilişkilerinde birçok problem ortaya çıkmakta ve bunlar maliyet olarak tanımlanmaktadır. Yani, "trafik sıkışıklığı büyük bir problemdir" ifadesi, ulaştırma otoriteleri ve ekonomistler tarafından "trafik sıkışıklığı önemli bir maliyettir" şeklinde ifade edilmektedir (Bakırc1, 2005).

Karayolu işletme maliyetleri değişken ve sabit maliyetler olarak sınıflandırabilir. Değişken maliyetler, tüketimdeki artıştan kaynaklanan artan maliyetler olarak kabul edilebilirler. Bu yüzden, örneğin değişken maliyetler araç kullanıcılarının yıllık araç kullanım mesafelerini düşürmeleri gibi tüketimdeki azalmayla azalabilecek maliyetleri yansıtırlar. Sabit maliyetler, ekipman, bina ya da arazi maliyetleri gibi kaçınılmaz maliyetler olup tüketim miktarından etkilenmezler (Bakırc1, 2005).

Ulaştırma sisteminin planlanması aşamasında, işletim sırasında karşılaşılacak maliyetlerin tanımlanması ve analiz edilmesi gerekmektedir. Karayolu ulaşımında işletme maliyetleri; taşıt işletme maliyeti, emisyon maliyeti, zaman kaybı maliyeti ve yol güvenliği maliyeti şeklindedir. Bu işletme maliyetlerinin ayrı ayrı belirlenmesi ve bunların etkilerinin değerlendirilmesi büyük önem arz etmektedir. Dünya Bankası tarafından yol projelerinin yapım ve işletim maliyetlerinin değerlendirilmesi amacıyla HDM-4 yazılımı geliştirilmiştir ve bu yazılım birçok ülkede yaygın olarak kullanılmaktadır. Bu yazılımın Dünya Bankası tarafından tanıtılması sonucunda, projelerin ömür döngü maliyet analizi ile değerlendirilmesi uluslararası düzeyde önemli hale gelmiştir. Ömür döngü maliyet analizi gelişmiş ve gelişmekte olan ülkelerde yaygın olarak kabul görmektedir (Ozbay vd., 2004). Ömür döngü maliyet analizi genel tanımıyla, bir projenin ekonomik verimliliğini değerlendirmek amacıyla kullanılan bir değerlendirme yöntemidir. Bu yöntemde önemli olan bu maliyetlerin en aza indirilebilmesine yönelik değerlendirmeler yapılmasıdır (Yüksekli, 2006). HDM-4 yazılımı; gelişmiş ve gelişmekte olan 100'den fazla ülkede kullanılmaktadır. Güney Afrika'da 2005 yılında tüm ulaştırma projeleri için ömür döngü maliyet analizlerini içermesi gerektiği konusunda bir politika kararı alınmıştır. Ayrıca, HDM-4 yazılımının ömür döngü maliyet analizi için kullanılması gerektiğine de karar verilmiştir (Burger vd., 2008).

Bu çalışmada HDM-4 yazılımı kullanılarak, yazılım parametrelerindeki değişimin işletme maliyetine etkisinin analiz edilmesi amaçlanmıştır. Çalışma kapsamında, parametre değişiminin etkisi projelendirilmiş bir yol güzergahı için belirlenerek, taşıt işletme, çevresel 
etkiler ve yol geometrik özelliklerine ilişkin kullanılan parametrelerin karayolu işletme maliyetine olan etkisi ortaya konulmuştur.

\section{KARAYOLU İŞLETME MALIYYETLERI}

HDM-4 yazılımında karayolu işletme maliyetleri; taşıt işletme maliyetleri, emisyon maliyetleri, yol güvenliği maliyetleri ve zaman kaybı maliyetleri olmak üzere dört ana başlıkta incelenebilir. Zaniewski vd, 1982 yılında Dünya Bankası ve Brezilya hükümeti için yaptığı çalışmada karayolu yapımı ve işletimine ilişkin maliyetleri incelemiştir (Zaniewski vd., 1982).

\subsection{Taşıt İşletme Maliyetleri}

Bir taşıtın işletme maliyeti, seyirden bağımsız olan sabit harcamaların yanısıra yakıt, yağ, lastik, bakım-onarım gibi taşıtın hareketi ile ortaya çıkan bazı harcamalardan oluşur. Taşıtın hareketi sonucu ortaya çıkan harcamalar ile yolun fiziki ve geometrik özellikleri arasında çok yakın bir ilişki vardır. Bir yolun ekonomik şekilde planlandığını öne sürebilmek için yolu kullanan taşıtların seyir ile ilgili işletme maliyetlerinin de mümkün olduğunca düşük olması gerekmektedir. Taşıt işletme maliyetleri genel olarak 4 başlıkta incelenebilir; yakıt maliyeti, yă̆ maliyeti, lastik maliyeti ve bakım-onarım maliyeti.

Bir aracın yakıt maliyeti; boyuna eğim, kaplama cinsi ve durumu, yatay kurbalar ve yoldaki trafik durumu gibi faktörlere bağlıdır. Yapılan çalışmalarda, rijit üst yapının esnek üst yapıya oranla yakıt tüketimi açısından daha ekonomik olduğu gözlemlenmiştir.

Motor yağı, şanzıman yağı, fren hidrolik yağı gibi bileşimler araç motorunun ve aktarma organlarının problemsiz çalışmasını sağlamaktadır. Bu yağların tüketimi; aracın kullanımına, trafik özelliklerine (akışkan, sıkışık vs.) ve yol karakteristik özelliklerine (boyuna eğim, kurp sayısı vs.) bağlı olarak değişmektedir.

Lastik maliyeti; lastiğin teknolojisi, taşıtın hızı, yol kaplamasının cinsi ve bakım standartları, yükleme durumu, ani ve aşırı düzensiz frenleme, küçük yatay kurp yarıçapları gibi faktörler nedeniyle lastiğin deforme olmasından kaynaklanan maliyettir. Örneğin kaplama cinsine göre, yuvarlanma direnci bakımından rijit üstyapının esnek üstyapıya oranla daha uygun bir kaplama olduğu gözlemlenmiştir. Gelişen teknoloji ve lastik tasarımlarındaki gelişmeler lastik maliyetini azaltmaya yönelik süregelmektedir.

Bakım ve onarım maliyeti; taşıt işletme maliyetleri arasında önemli bir kısmı oluşturmaktayken, hassas bir şekilde hesaplanması zor olmaktadır. Bireysel araçlarda masraflar 
Canver, S., Özen, H., Saraçoğlu, A. \& Maltaş, A.

araç sahibine ve araç ruhsat koşullarına bağlı olarak değiş̧ebilmektedir. Genel taşıt sınıfları için güncel bakım ve onarım masraflarını tahmin edebilmek için araç parçaları ve işçilik maliyetleri gibi bazı bilgi ve yöntemlere ihtiyaç duyulmaktadır.

\subsection{Emisyon Maliyetleri}

Geçmiş yıllarda emisyon salınımı konusunda yapılan çalışmalarda hafif ve ağır taşıtlar arasında önemli farklılıklar olduğu görülmüştür. Hafif taşıtlar için en iyi emisyon modellemesi Kunselman ve arkadaşları tarafından çalışılmıştır. Model, 18 farklı hafif taşıt grubu ve düşük rakımlı kentler için tasarlanmıştır. Ağır taşıtlar için emisyon modellemesine ilişkin tatmin edici pek fazla çalışma bulunmamakla beraber iki çalışma ön plana çıkmaktadır. Güney Batı Araştırma Enstitüsü emisyonla alakalı önemli miktarda veri elde etmiş ama bunlar daha çok emisyon sertifika prosedürlerinin gelişimi ve test edilmesi için elde edilmiştir (Zaniewski vd., 1982).

Emisyon salınımının modellenmesinde ortalama hız, tekil emisyon faktörleri, yakıt tüketimi gibi yaklaşımlardan faydalanılmaktadır. Ortalama hız yaklaşımında taşıt tipi ve emisyon bileşimi için ortalama hız ve emisyon düzeyi (gr/taşıt-km) arasındaki ilişkiyi değerlendirmektedir. Toplam emisyon seviyesi hız ve toplam yolculuk uzunluğu ile çarpılarak elde edilir. Tekil emisyon faktörleri yaklaşımında sürüş etkileri göz ardı edilmektedir. Emisyon miktarının hesaplanmasında farklı taşıt tiplerinin yolculuk miktarları kullanılmaktadır. Yakıt tüketimi yaklaşımında ise emisyon miktarı yol koşulları, geometrik tasarım ve motor fonksiyonlarının değişimine bağlı olarak hesaplanmaktadır (Narwal, 2016). Çalışmada kullanılan HDM-4 programı emisyon hesabında yakıt tüketimi yaklaşımına dayanarak hesap yapmaktadir.

\subsection{Yol Güvenliği Maliyetleri}

Yol güvenliği maliyetleri, karayolunda meydana gelen kazaların neden olduğu maddi ve manevi maliyetler olarak ifade edilebilir. Yol güvenliği maliyetinin hesabı, kullanılan yolun tabaka koşulları ve meydana gelen kaza sayıları arasında ilişki kurulabilmesi açısından önemlidir. Günümüzde gerçekleşen kazaların büyük çoğunluğu aşırı hızdan kaynaklanmaktadır. Sürücüler çeşitli unsurlara bağlı olarak kendilerini güvende hissettikleri hızlarda araç kullanmaktadırlar. Hız ile trafik kazaları arasında üç farklı ilişki bulunmaktadır. Birincisi; hızın yol üzerindeki kullanıcılara tepki vermek için ihtiyaç duyduğu süreyi doğrudan etkilemesidir. İkincisi; yol üzerindeki taşıtlar arasında veya bu taşıtlar ile yol kenarındaki 
nesneler arasındaki hız farklılıklarının çarpışma olasılığını etkilemesidir. Üçüncüsü; çarpışma olduğunda yüksek hızın ciddi manada maddi ve manevi hasarlara yol açmasıdır. Kısacası karayolu trafiğindeki kayıplarda hız, hem kaza olma ihtimalini arttırmakta hem de bunlardan kaynaklanan kayıpların derecesini etkileyen kilit etmenlerden biri olarak tanımlanmaktadır (KGM, 2014).

\subsection{Zaman Kaybi Maliyetleri}

Trafik tıkanıkları gibi nedenlerden kaynaklanan zaman kayıpları, yol kullanıcılarına tünel, köprü ve otoyol gibi yapılarda geçiş ücreti olarak yansımaktadır. Fiyatlandırmayı etkilemekte ve genellikle trafik sıkışıklığı maliyetlerinin vergilendirilmesi yoluyla yönetilmektedir (Zaniewski vd., 1982).

Zaman kaybı maliyeti ulaştırmanın işletme maliyetleri içerisindeki en büyük maliyetlerden biri olup zaman kaybı maliyetinden tasarruf etmek altyapı yatırımlarının hayata geçirilmesindeki en önemli gerekçelerden biridir. Seyahat süresi, seyahat konforu ve seyahat güvenilirliği zaman kaybı maliyetini belirleyen niceliklerdir (VTPI, 2018).

Seyahat süresi değerleri, ulaştırma planlaması ve proje değerlendirmesi açısından önemli bir faktördür. Bu değerler seyahat sistemi değişikliğine sebep olan seyahat davranışları üzerindeki etkileri tahmin edebilmek için kullanılır. Seyahat süresi tasarrufları, yeni otoyol yapımı ya da yol genişletmesi gibi ulaşım gelişim projelerinin uygulanmasıyla elde edilen en büyük kazançtır. Sonuç olarak seyahat süresi değerlendirmesi sonuçlara etki eden önemli bir faktördür. Seyahat süresinin tek bir yöntemle tek bir değişkenle ölçülmesi bazı durumlarda projenin uygun maliyetli olduğu sonucunu ortaya çıkarsa da farklı yöntemlerle ve farklı bakış açılarıyla yeniden ölçülerek yapılan çalışmada bu proje uygun maliyetli olmayabilir. Ulaşım planlama ve değerlendirme modellemelerle geliştirilen seyahat süresi değerleri, daha hassas analizler yapabilmeyi ve daha uygun maliyetli çözümler üretmeyi sağlayabilir. Seyahat süresi birim maliyetleri genellikle ortalama ücretlere dayanarak hesaplanmaktadır. Kişisel seyahat süresi değerleri, çalışma ücretinin \%25 ila \%50’si arasında değişmektedir (Tranter, 2004). 
Canver, S., Özen, H., Saraçoğlu, A. \& Maltaş, A.

\section{KARAYOLU İŞLETME MALIYETİ HESABI: GELİBOLU-ECEABAT-ABİDE VE ANIT DEVLET YOLU ÖRNEĞI}

$\mathrm{Bu}$ çalışmada, "Gelibolu-Eceabat-Abide ve Anıt Devlet Yolu-3. Kısım" projesi örneğinde taşıt işletme, çevresel etkiler ve yol geometrik özelliklerine ilişskin kullanılan parametrelerin yol işletme maliyetine olan etkileri incelenmiştir.

Tablo 1. Proje bilgileri

\begin{tabular}{|l|l|}
\hline Km & $0+000,00-13+594,15$ \\
\hline Yolun sınıfı & $2 \times 1$ bölünmemiş yol \\
\hline Platform genişliği & $5,00-8,00 \mathrm{~m}$ \\
\hline Şerit sayısı & $2 \times 1$ \\
\hline Şerit genişliği & $3,00 \mathrm{~m}$ \\
\hline Orta refüj genişliği & Yok \\
\hline Tretuvar & Yok \\
\hline Banket genişliği & $1,00 \mathrm{~m}$ \\
\hline Geçiş eğrisi (klotoid) & Var \\
\hline Proje hızı & Ortalama 50 km/saat \\
\hline Maksimum boyuna eğim & $\% 8,00$ \\
\hline Kamulaştırma genişliği & Projenin gerektirdiği kadar \\
\hline Üst yapı cinsi & Bitümlü Sıcak Karışım \\
\hline Tırmanma şeridi & Yok \\
\hline
\end{tabular}

Bu devlet yolunun uzunluğu $13,59 \mathrm{~km}$ olup $2 \mathrm{x} 1$ şeritli bölünmemiş yol olarak projelendirilmiştir. Proje ile ilgili geometrik standartlar Tablo 1'de verilmiştir. Ayrıca, Şekil 1 'de projenin konumu hava fotoğrafinda gösterilmiştir.

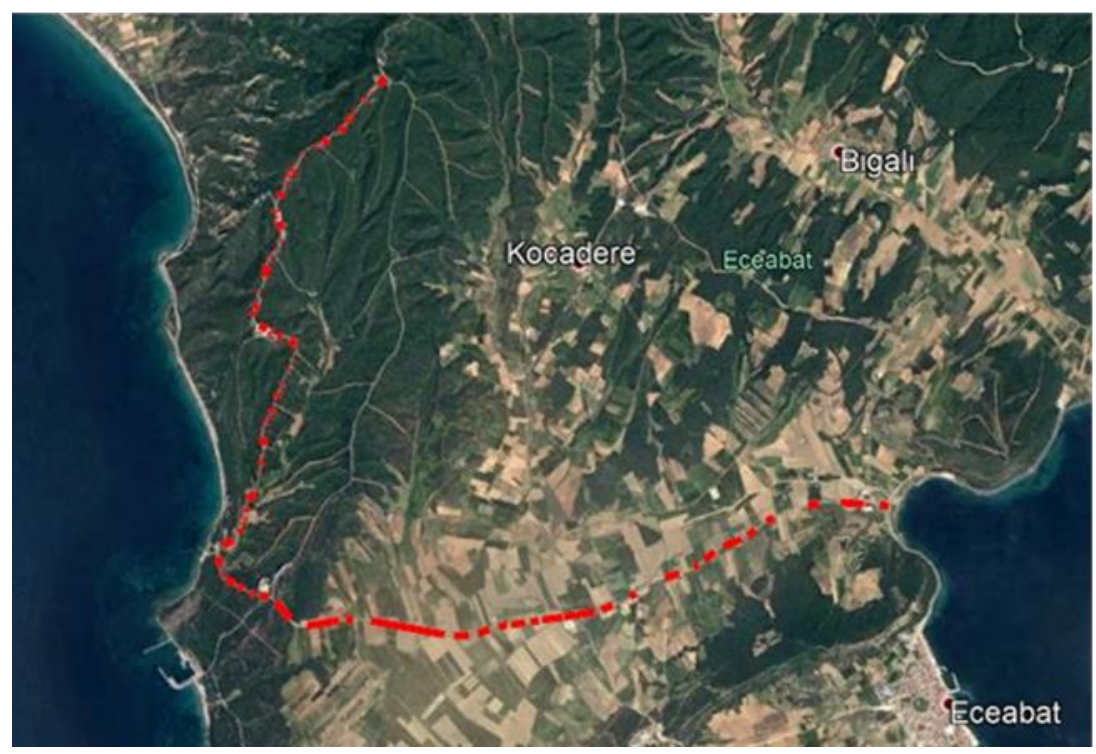

Şekil 1. Gelibolu-Eceabat-Abide ve Anıt Devlet Yolu konumu 


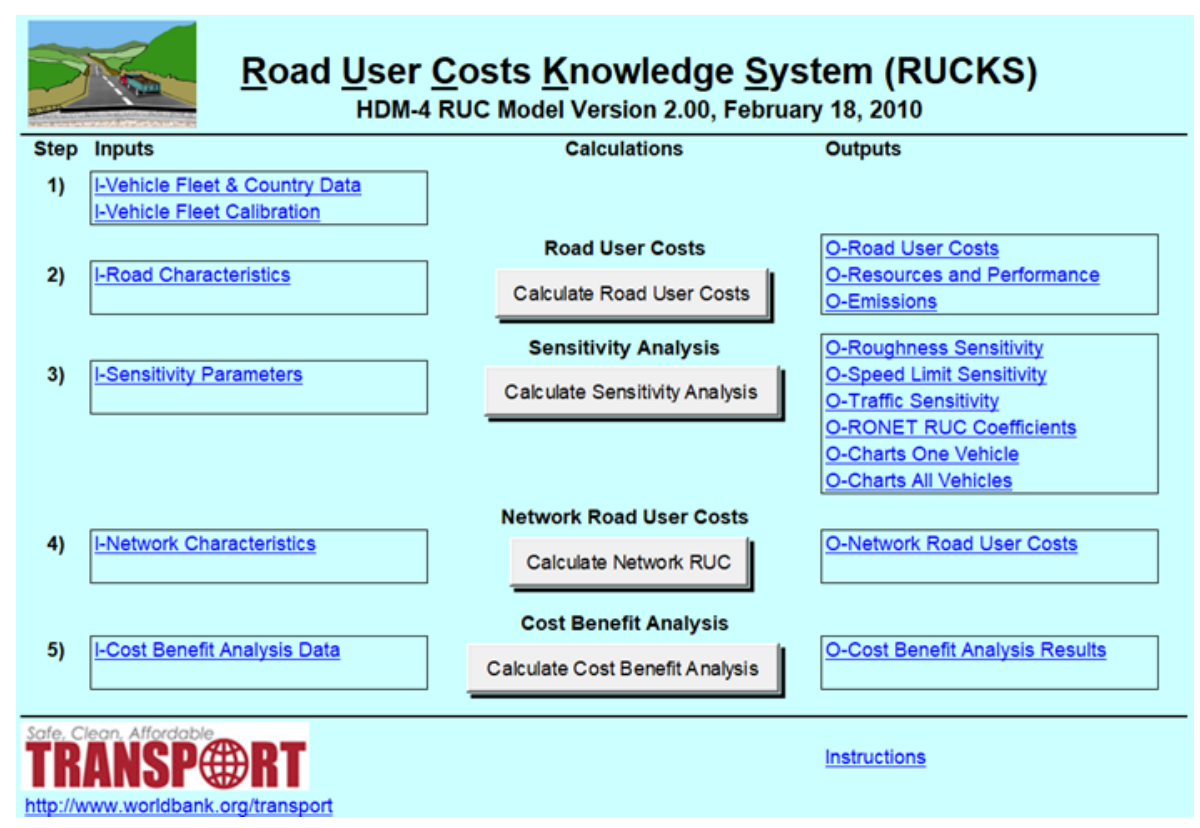

Şekil 2. HDM-4 yazılımı arayüzü

Şekil 2'de arayüzü gösterilen HDM-4 yazılımı ile yol kullanıcı maliyetleri analizi 5 adımda tamamlanmaktadır. Bu adımlar aşağıdaki şekilde sıralanabilir:

1. "Vehicle Fleet \& Country Data" hücresine araç filo birim maliyetleri ve araç karakteristik özellikleri girilir. Değerlendirme yapılması istenilmeyen araç tipinin "New Vehicle" hücresine sıfır yazılır.

2. "Vehicle Fleet Calibration" hücresinde tüm araç filolarının parametreleri ayarlanır.

3. "Road Characteristics" hücresi içerisimde yolun karakteristik özellikleri belirlenir.

4. "Calculate Road User Costs" butonuna tıklanıldığında Yol Kullanıcı Maliyetleri ve emisyonları hesaplatılır.

5. "Road User Costs" sekmesi kullanılarak birim yol kullanıcı maliyetleri ve hızlar görüntülenebilir. "Resources and Performance" sekmesinde ise kaynak tüketimi ve araç performansını gözlemlenmektedir. Son olarak "Emissions" sekmesi de hesaplanan emisyon değerlerini göstermektedir.

HDM-4 yazılımı; ekonomik, teknolojik ve iklimsel olarak farklı olan 100'den fazla ülkede kullanılmaktadır. Yazılım gelecekteki değişimleri simüle etme imkânı sağladığından dolayı sonuçların güvenilirliği iki temel hususa bağlıdır. Bunlar: 
Canver, S., Özen, H., Saraçoğlu, A. \& Maltaş, A.

- Model girdilerinin mevcut durumdaki gerçek koşulları iyi derecede yansıtabilir olması ve,

- Model tahminlerinin çeşitli koşullar altında gerçek davranışlara iyi derecede uyumlu olmasidir.

$\mathrm{Bu}$ nedenle, analiz yapılmadan önce ilgili bölgenin mevcut durum koşullarına göre yazılımın kalibre edilmesi gerekmektedir (Das vd, 2013).

\subsection{Uygulama Girdileri}

“Gelibolu-Eceabat-Abide ve Anıt Devlet Yolu-3. Kısım” projesi için Çanakkale il sınırlarında yer alan bölge ile ilgili bilgiler uygulama girdileri olarak kullanılmıştır. Uygulama girdileri, seyahat süresi, emisyon değerleri, yol güvenliği, yol geometrisi gibi verileri içermektedir. Yol kullanıcı maliyetlerinin tam olarak hesaplanabilmesi için öncelikle seyahat süresi maliyetlerinin belirlenebilmesi gerekmektedir. Bu amaçla, Çanakkale bölgesi için otobüs ile seyahat bazında seyahat süresi değerleri hesaplanmıştır.

TÜİK'den elde edilen bilgilere göre; Türkiye genelinde 15 ve üzeri yaşındakiler arasında 2015 yılı Haziran döneminde işsiz sayısı 2 milyon 880 bin kişi ve işsizlik oranı ise \%9,6 seviyesinde gerçekleşmiştir. Aynı dönemde işgücü sayısı 30 milyon 141 bin kişi, işgücüne katılma oranı ise \%52,1 olarak belirlenmiştir. Buna göre, Türkiye'deki çalışan sayısı;

Çalışan Sayısı = Nüfus * İş gücüne katılım oranı * $(1-$ İşsizlik oranı $)$

Çalışan sayısı $=78.741 .053 *(\% 52,1) *(1-\% 9,6)=37.085 .776$ kişi olarak hesaplanmıştır.

Çanakkale şehri Balıkesir şehri ile birlikte, TÜİK İstatistiki Bölge Birimleri Sınıflaması 2. Düzey TR22 bölgesinde yer almaktadır. Bu bölge için çalışan sayılarının Türkiye toplamı içindeki payı 2011 yılında \%1,77 olarak belirlenmiştir. Bu durumda bölgedeki toplam çalışan nüfusu 37.085.776 * 0,0177 = 656.418 olarak bulunmaktadır. Bölgedeki toplam nufüs ise 1.665.089'dur. Buna göre, ortalama çalışan yüzdesi $656.418 / 1.665 .089=\% 39,4$ olarak hesaplanmaktadır.

TÜİK verilerine göre TR22 istatistiki bölgesinde kişi başına gayri safi katma değer 2011 yılında 8.954 \$ olarak gerçekleşmiştir. Buna göre bölgenin toplam gayri safi katma değeri 8.954 * 1.665.089 = 14.909.206.000 \$ olarak bulunmaktadır. 2011 yılı döviz kuru için 1 Amerikan 
doları ortalama 1,678 Türk Lirası olarak alınırsa, bölgenin toplam gayri safi katma değeri 14.909.206.000 * 1,678 $=25.017 .647 .668$ TL olmaktadır.

Tablo 2'de TR22 istatistiki bölgesi için otobüsle seyahat süresi değerinin belirlenmesine yönelik işlemler adım adım gösterilmiştir. Tabloda görüldüğü gibi, otobüs ile seyahat süresi değeri, çalışma saatleri içinde 9,85 TL/saat ve dişında 2,22 TL/saat olarak bulunmuştur. $\mathrm{Bu}$ değerler kullanılarak Tablo 3'de diğer taşıt türleri için seyahat süresi değerleri belirlenmiştir.

Tablo 2. Otobüsle seyahat süresi değerinin belirlenmesi

\begin{tabular}{|l|l|l|l|}
\hline Parametre & Formül & Birim & Miktar \\
\hline Haneye düşen G.S.K.D (\%70) (D) & $\mathrm{D}=\mathrm{A}^{*} 0,70$ & $\mathrm{TL}$ & 17.512 .352 .000 \\
\hline Çalışan Ortalama Geliri (E) & $\mathrm{E}=(\mathrm{D} / \mathrm{B}) / \mathrm{C}$ & $\mathrm{TL} / \mathrm{Y}$ ıl & 26.693 \\
\hline Çalışan Ortalama Geliri (saat) (F) & $\mathrm{F}=\mathrm{E} / 3120$ & TL/Saat & 7,41 \\
\hline $\begin{array}{l}\text { Seyahat süresi değeri (G) } \\
\text { (Çalışma saatleri içindeki değer) }\end{array}$ & $\mathrm{G}=\mathrm{F}^{*} 1,33$ & TL/Saat & 9,85 \\
\hline $\begin{array}{l}\text { Seyahat süresi değeri (G) } \\
\text { (Çalış̧ma saatleri dışındaki değer) }\end{array}$ & $\mathrm{G}=\mathrm{F}^{*} 0,30$ & TL/Saat & 2,22 \\
\hline A = Gayri Safi Katma Değer (G.S.K.D); B $=$ Bölge nüfusu; $C=$ Çalışan yüzdesi \\
\hline
\end{tabular}

Tablo 3. Diğer taşıt türleri için seyahat süresi değerleri

\begin{tabular}{|l|l|c|c|}
\cline { 3 - 4 } \multicolumn{2}{c|}{} & $\begin{array}{l}\text { Çalısma Saatleri } \\
\text { İçinde (TL/saat) }\end{array}$ & $\begin{array}{l}\text { Çalışma Saatleri } \\
\text { Dişında (TL/saat) }\end{array}$ \\
\hline Otobüs & Otobüs *1,00 & 9,85 & 2,22 \\
\hline Mini Otobüs & Otobüs * 1,20 & 11,82 & 2,66 \\
\hline İki Tekerlekli & Otobüs * 1,40 & 13,79 & 3,11 \\
\hline Araba & Otobüs *1,75 & 17,24 & 3,88 \\
\hline Üç Tekerlekli & Araba *0,70 & 12,07 & 4,07 \\
\hline
\end{tabular}

Seyahat süresi maliyetinin yanı sıra emisyon maliyeti de hesaplanmalıdır. Yakıt tüketimine bağlı olarak değişen zararlı bileşenlerin insan sağlığı için zararları belli bir maliyet ile ifade edilmektedir. Bu çalışmada girdi olarak CO2 salınım maliyeti kullanılmıştır. Her bir kilo CO2 salınımının insan sağlığına etkisi 0,02 \$ olarak alınmıştır. Buna göre, ülkemiz için $\mathrm{CO} 2$ emisyonunun birim fiyat1 $20 \$ /$ ton $* 1,678(2011 \mathrm{kuru})=33,56 \mathrm{TL} / \mathrm{ton}$ olarak hesaplanmıştır.

Yol güvenliği maliyeti girdisi yine 2011 y1lı TÜİK verilerine göre ülkemizde 1.228.928 tane trafik kazası gerçekleşmiştir. Bu kazalarda 238.074 kişi yaralanırken 3.835 kişi ise hayatını kaybetmiştir. Buna göre, yaralanma ve ölüm oranları 1/62 olarak elde edilmiştir. Kişi başına gayri safi katma değer $8.954 * 1,678=15.025$ TL ve bir insanın ortalama yaşam süresi 75 yıl alınarak yol güvenliği maliyeti girdileri Tablo 4'de hesaplanmıştır. 
Canver, S., Özen, H., Saraçoğlu, A. \& Maltaş, A.

Tablo 4. Yol güvenliği maliyeti girdileri

\begin{tabular}{|l|l|}
\hline Gayri Safi Katma Değer (TL/kişi) & 15.025 \\
\hline Yaşam süresi (yıl) & 75 \\
\hline Yaralanma maliyetinin ölüm maliyetine oranı & $\% 25$ \\
\hline Ölüm maliyeti (TL/ölüm) & 1.126 .875 \\
\hline Ciddi yaralanma maliyeti (TL/yaralanma) & 281.718 \\
\hline
\end{tabular}

Yol karakteristikleri kısmındaki yol geometrisi ile ilgili bilgileri girebilmek için ilgili projenin yatay ve düşey planlarından faydalanılmıştır. Öncelikle projedeki toplam düşey kot artışlarının ve azalmalarının toplamını ifade eden "Rise\&Fall $(\mathrm{m} / \mathrm{km})$ " değeri hesaplanmıştır. Şekil 3'de düşey kot artış ve azalmaları şematik olarak gösterilmiştir. Buna göre "Rise \& Fall $(\mathrm{m} / \mathrm{km})$ " değeri; Rise\&Fall $=(\mathrm{R} 1+\mathrm{R} 2+\mathrm{R} 3+\mathrm{F} 1+\mathrm{F} 2) /$ Uzunluk $(\mathrm{m} / \mathrm{km})$ bağıntısıyla elde edilmektedir. Çalışma kapsamında kullanılan proje için, "Rise\&Fall” değeri 22,21 (m/km) olarak hesaplanmıştır.

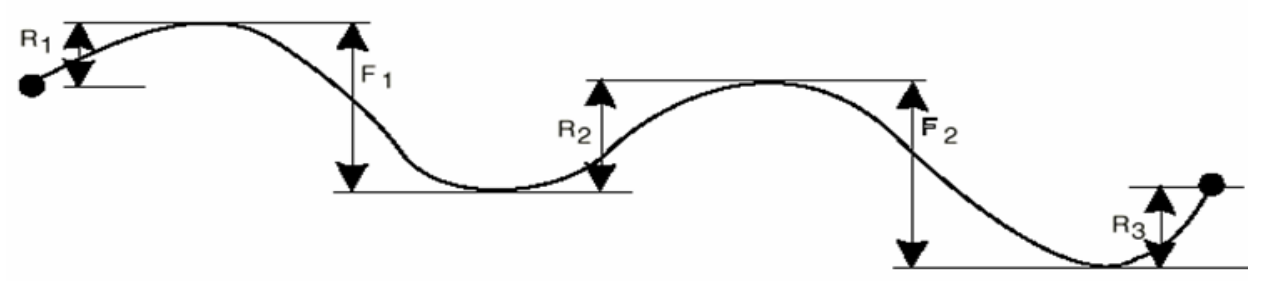

Şekil 3. Rise\&Fall şematik gösterimi

Diğer taraftan, yatay kurpların eğrilik açıları toplamının toplam yol uzunluğuna bölünmesiyle elde edilen "Horizontal Curvature (derece/km)" değeri de yol geometrisi girdisi olarak kullanılmaktadır. Şekil 4'de yatay kurpların geometrisi şematik olarak gösterilmiştir. Buna göre "Horizontal Curvature (derece/km)" değeri; Horizontal Curvature = $(\mathrm{C} 1+\mathrm{C} 2+\mathrm{C} 3+\mathrm{C} 4) /$ Uzunluk (derece/km) bağıntısıyla elde edilmektedir. İlgili proje için, "Horizontal Curvature” değeri ise 63,23 (derece/km) olarak hesaplanmıştır.

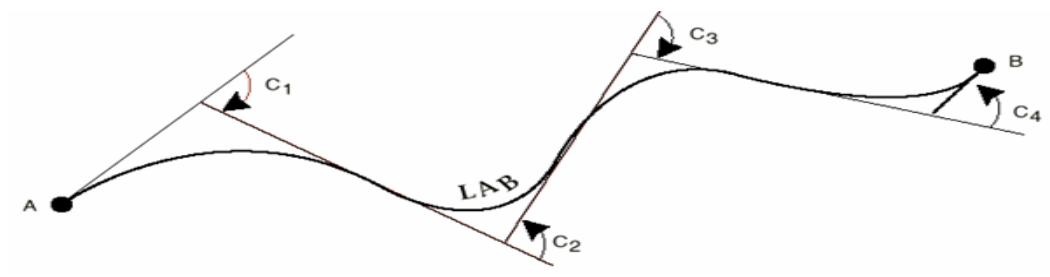

Şekil 4. Horizontal Curvature şematik gösterimi

Son olarak, ilgili projeye ait yol trafik bilgileri girilmiştir. Belirlenen Y1llık Ortalama Günlük Trafik (YOGT) değerleri; 1 treyler, 81 kamyon, 130 otobüs, 1 orta yüklü ticari taşıt ve 
445 otomobil şeklindedir. Gelecek yıllar için öngörülen trafik artış oranları, treyler ve kamyon için $\% 4$, otobüs, orta yüklü ticari taşıt ve otomobil için $\% 5$ olarak kabul edilmiştir. Taşıt eşdeğerlik faktörü olarak treyler için 4,10, kamyon için 2,90, otobüs için 3,20, orta yüklü ticari taşıt için 0,60 ve otomobil için 0,0006 olarak kabul edilmiştir.

\subsection{Uygulama Çıktıları}

Program girdilerini belirledikten sonra programın arayüzünde de gösterilen "Calculate Road User" butonuna basılarak maliyetler elde edilmiştir. Bu maliyetler; yol kullanıcı maliyetleri, kaynaklar ve taşıt performansları ve emisyon miktarları olmak üzere üç başlıkta analiz edilmiştir.

Şekil 5'e göre toplam yol kullanıcı maliyetlerinin \%48,4'ünü taşıt işletme maliyetlerinin $\% 41,2$ 'sinin zaman kaybı maliyetinin \%9,9'nun yol güvenliği maliyetinin ve \%0,6'nın emisyon maliyetinin oluşturduğu tespit edilmiştir.

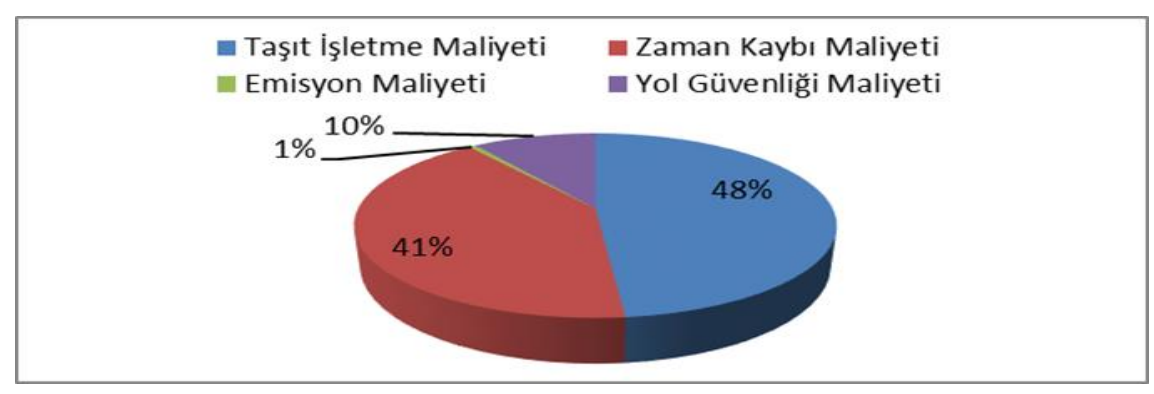

Şekil 5. Toplam yol kullanıcı maliyetleri yüzdeleri

Yol kullanıcı maliyetleri; taşıt işletme maliyetleri, zaman kaybı maliyeti emisyon maliyeti ve yol güvenliği maliyetlerinin toplamı şeklinde gösterilmiştir. Taşıt filosundaki herhangi bir aracın 1 km'lik seyahati boyunca kullanıcıya yansıyan taşıt işletme giderleri 0,910 TL/taşıt-km, zaman kaybı maliyeti 0,774 TL/taşıt-km, emisyon maliyeti 0,011 TL/taşıt-km ve yol güvenliği maliyeti $0,186 \mathrm{TL} /$ taşıt-km olarak hesaplanarak toplam taşıt filosunun yol kullanıcı maliyeti 1,881 olarak bulunmuştur (Tablo 5). 
Canver, S., Özen, H., Saraçoğlu, A. \& Maltaş, A.

Tablo 5. Yol kullanıcı maliyetleri (HDM-4)

\begin{tabular}{|c|c|c|c|c|c|c|}
\hline Maliyetler & Otomobil & $\begin{array}{l}\text { Orta Yüklü } \\
\text { Ticari Taşıt }\end{array}$ & Kamyon & Tir & Otobüs & $\begin{array}{c}\text { Ortalama } \\
\text { Taşıt Filosu }\end{array}$ \\
\hline Yol Kullanıcı Maliyetleri (TL/taşıt-km) & 1,159 & 1,130 & 1,718 & 2,893 & 4,451 & 1,881 \\
\hline Taşıt İşletme Maliyeti (TL/taşıt-km) & 0,691 & 0,794 & 1,427 & 2,639 & 1,323 & 0,910 \\
\hline Yakıt (TL/taşıt-km) & 0,495 & 0,529 & 0,871 & 1,710 & 0,757 & 0,595 \\
\hline Yağlar (TL/taşıt-km) & 0,006 & 0,008 & 0,016 & 0,032 & 0,017 & 0,009 \\
\hline Tekerlek (TL/taşıt-km) & 0,006 & 0,011 & 0,037 & 0,082 & 0,030 & 0,015 \\
\hline Bakım Parçaları (TL/taşıt-km) & 0,052 & 0,055 & 0,177 & 0,415 & 0,141 & 0,086 \\
\hline Bakım İşi (TL/taşıt-km) & 0,010 & 0,008 & 0,081 & 0,110 & 0,066 & 0,030 \\
\hline Ekip Zaman Maliyeti (TL/taşıt-km) & 0,000 & 0,040 & 0,073 & 0,071 & 0,075 & 0,024 \\
\hline Amortisman (TL/taşit-km) & 0,095 & 0,105 & 0,108 & 0,139 & 0,156 & 0,108 \\
\hline Faiz (TL/taşit-km) & 0,027 & 0,027 & 0,035 & 0,057 & 0,055 & 0,034 \\
\hline Genel Masraflar (TL/taşıt-km) & 0,000 & 0,011 & 0,029 & 0,024 & 0,026 & 0,009 \\
\hline Zaman Maliyetinin Değeri (TL/taşıt-km) & 0,270 & 0,082 & 0,028 & 0,027 & 2,976 & 0,774 \\
\hline Yolcu Süresi (TL/taşıt-km) & 0,270 & 0,082 & 0,027 & 0,026 & 2,976 & 0,774 \\
\hline Yük Süresi (TL/taşıt-km) & 0,000 & 0,000 & 0,001 & 0,001 & 0,000 & 0,000 \\
\hline Emisyon Maliyeti (TL/taşıt-km) & 0,008 & 0,010 & 0,019 & 0,037 & 0,016 & 0,011 \\
\hline Yol Güvenliği Maliyeti (TL/taşıt-km) & 0,190 & 0,244 & 0,244 & 0,190 & 0,136 & 0,186 \\
\hline Yol Kullanıcı Maliyetleri (\%) & $100,0 \%$ & $100,0 \%$ & $100,0 \%$ & $100,0 \%$ & $100,0 \%$ & $100,0 \%$ \\
\hline Taşıt İşletme Maliyeti (\%) & $59,6 \%$ & $70,3 \%$ & $83,0 \%$ & $91,2 \%$ & $29,7 \%$ & $48,4 \%$ \\
\hline Zaman Maliyetinin Değeri (\%) & $23,3 \%$ & $7,2 \%$ & $1,7 \%$ & $0,9 \%$ & $66,9 \%$ & $41,2 \%$ \\
\hline Emisyon Maliyeti (\%) & $0,7 \%$ & $0,9 \%$ & $1,1 \%$ & $1,3 \%$ & $0,4 \%$ & $0,6 \%$ \\
\hline Yol Güvenliği Maliyeti (\%) & $16,4 \%$ & $21,6 \%$ & $14,2 \%$ & $6,6 \%$ & $3,0 \%$ & $9,9 \%$ \\
\hline Taşıt Hızı $(\mathrm{km} / \mathrm{sa})$ & 103,2 & 99,4 & 81,6 & 84,6 & 80,1 & 99,8 \\
\hline Günlük Trafik (taşıt/gün) & 445 & 1 & 81 & 1 & 130 & 658 \\
\hline
\end{tabular}

Tablo 6. Taşıt işletme maliyetleri (HDM-4)

\begin{tabular}{|l|c|c|c|c|c|c|}
\hline \multicolumn{1}{|c|}{ Maliyetler } & Otomobil & $\begin{array}{c}\text { Orta Yüklü } \\
\text { Ticari Taşıt }\end{array}$ & Kamyon & Tur & Otobüs \\
\hline Taşıt İşletme Maliyeti & 103,12 & 110,20 & 212,40 & 416,96 & 184,54 \\
\hline Yakıt (litre) & 0,69 & 0,98 & 2,01 & 3,98 & 2,14 \\
\hline Yağlar (litre) & $1,44 \%$ & $1,75 \%$ & $1,15 \%$ & $1,17 \%$ & $1,10 \%$ \\
\hline Tekerlek (yeni bir lastik fiyatının \%'si) & $0,20 \%$ & $0,14 \%$ & $0,22 \%$ & $0,26 \%$ & $0,10 \%$ \\
\hline Bakım Parçaları (yeni araç maliyetinin \%'si) & 2,58 & 2,10 & 10,13 & 13,72 & 8,27 \\
\hline Bakım İşi (saat) & & 10,06 & 12,25 & 11,82 & 12,49 \\
\hline Ekip Zaman Maliyeti (saat) & $0,37 \%$ & $0,27 \%$ & $0,14 \%$ & $0,09 \%$ & $0,11 \%$ \\
\hline Amortisman (yeni araç maliyetinin \%'si) & $0,11 \%$ & $0,07 \%$ & $0,04 \%$ & $0,04 \%$ & $0,04 \%$ \\
\hline Faiz (yeni araç maliyetinin \%'si) & \multicolumn{5}{|c|}{} \\
\hline Zaman Maliyetinin Değeri & 9,7 & 10,1 & 12,2 & 11,8 & 12,5 \\
\hline Yolcu Süresi (saat/yolcu) & 9,7 & 10,1 & 12,2 & 11,8 & 12,5 \\
\hline Yük Süresi (saat/taşıt) & 9,7 & 9,07 & 4,71 & 2,40 & 5,42 \\
\hline Yakıt Tüketimi (km/litre) & 1452 & 1022 & 498 & 252 & 468 \\
\hline Yağ Tüketimi (km/litre) & 69224 & 57025 & 87054 & 85657 & 90813 \\
\hline Tekerlek Ömrü (km)
\end{tabular}


Tablo 6'da yol kullanıcı maliyetlerinin büyük kısmını oluşturan taşıt işletme maliyetleri görülmektedir. Her 1000 taşıtın 1 km'lik seyahati boyunca tükettiği kaynaklar gösterilmiştir. Yakıt tüketimi bu maliyetler içerisindeki en önemli maliyettir. Ağır taşıtların taşıt işletme maliyetlerinin daha fazla olduğu gözlemlenmiştir.

Tablo 7'de salınım yapılan bileşenlerin miktarları görülmektedir. En fazla miktarda salınımı CO2 bileşeninin yaptığı ve diğer bileşenlerin ise göz ardı edilecek kadar az miktarda salınım yaptıkları tespit edilmiştir.

Tablo 7. Emisyon maliyetleri (HDM-4)

\begin{tabular}{|c|c|c|c|c|c|c|}
\hline & Otomobil & $\begin{array}{l}\text { Orta Yüklü } \\
\text { Ticari Taşıt }\end{array}$ & Kamyon & Tir & Otobüs & \\
\hline Taşıt Hızı $(\mathrm{km} / \mathrm{sa})$ & 103,2 & 99,4 & 81,6 & 84,6 & 80,1 & \\
\hline Taşıt Hızı (m/sn) & 28,7 & 27,6 & 22,7 & 23,5 & 22,2 & \\
\hline Taşıt Ömrü (yıl) & 10 & 10 & 11 & 11 & 10 & \\
\hline Yakıt Tüketimi (km/litre) & 9,70 & 9,07 & 4,71 & 2,40 & 5,42 & \\
\hline Yakıt Tüketimi (mil/galon) & 22,81 & 21,34 & 11,07 & 5,64 & 12,75 & \multirow{3}{*}{$\begin{array}{c}\text { Emisyon } \\
\text { Maliyetleri } \\
\text { (TL/ton) } \\
\end{array}$} \\
\hline Yakıt Tüketimi (litre/100km) & 10,31 & 11,02 & 21,24 & 41,70 & 18,45 & \\
\hline Yakıt Tüketimi (ml/sn) & 2,96 & 3,04 & 4,82 & 9,80 & 4,10 & \\
\hline Karbondioksit $-\mathrm{CO}_{2}(\mathrm{~g} / \mathrm{km})$ & 243,646 & 290,929 & 560,087 & 1099,489 & 487,183 & 33,6 \\
\hline Karbonmonoksit - CO (g/km) & 1,211 & 1,122 & 2,233 & 4,383 & 1,879 & 0,0 \\
\hline Hidrokarbon - HC $(\mathrm{g} / \mathrm{km})$ & 0,182 & 1,137 & 2,338 & 4,590 & 1,904 & 0,0 \\
\hline Nitrözoksit - NOx (g/km) & 1,551 & 4,030 & 8,175 & 16,048 & 6,749 & 0,0 \\
\hline Partiküller - Par (g/km) & 0,011 & 0,224 & 0,447 & 0,877 & 0,376 & 0,0 \\
\hline Sülfürdioksit- $\mathrm{SO}_{2}(\mathrm{~g} / \mathrm{km})$ & 0,077 & 0,948 & 1,827 & 3,586 & 1,587 & 0,0 \\
\hline Kurşun - Pb (g/km) & 0,031 & 0,000 & 0,000 & 0,000 & 0,000 & 0,0 \\
\hline Emisyon Maliyeti (TL/ton-km) & 0,008 & 0,010 & 0,019 & 0,037 & 0,016 & \\
\hline
\end{tabular}

\subsection{Duyarlılık Analizleri}

$\mathrm{Bu}$ bölümde kaplama pürüzlülüğü, trafik hacmi ve yol geometrik özellikleri parametrelerine bağlı olarak karayolu işletme maliyetlerinin değişimleri incelenmiştir. $\mathrm{Bu}$ parametrelerin taşıt hızları üzerindeki etkileri çok önemlidir. Taşıt hızları; emisyon düzeyi, trafik hacmi, yakıt tüketimi gibi faktörleri etkilemektedir. Dolayısıyla karayolu işletme maliyetlerinin hesaplanmasında belirleyici rol oynamaktadırlar.

Yol pürüzlülüğü yolun kaplama yüzeyinin karakteristik özelliklerini, kullanılan kaplamanın sürüş kalitesine etkilerini ve buna bağlı olarak yolun servis indeksini belirleyen bir parametredir. Yol pürüzlülüğü taşıt hızına etki eden önemli bir faktördür. Ayrıca fiziksel olarak taşıta doğrudan etkisi olduğu için bakım ve onarım maliyetini önemli ölçüde etki etmektedir. Tablo 8'de yol pürüzlülüğüne bağlı olarak yol kullanıcı maliyetleri görülmektedir. Uygulama 
Canver, S., Özen, H., Saraçoğlu, A. \& Maltaş, $A$.

örneğinde pürüzlülük değeri $2.0(\mathrm{~m} / \mathrm{km})$ kabul edilmiştir. Buna göre kullanıcı maliyeti 1,881 (\$/taşıt-km) olarak hesaplanmıştır. Plansız ve standartlara uygun olmayan yollarda kullanıma geçtiği yıldan itibaren çevresel etkilerden ve kapasitenin artmasıyla pürüzlülük değerinde artış görülmektedir.

Tablo 8. Farkl1 yol pürüzlülügüne göre birim maliyetler (HDM-4) (TL/taşıt-km)

\begin{tabular}{|c|c|c|c|c|c|c|}
\hline $\begin{array}{c}\text { Yol Pürüzlülüğü } \\
\text { (IRI, m/km) }\end{array}$ & Otomobil & $\begin{array}{c}\text { Orta Yüklü } \\
\text { Ticari Taşıt }\end{array}$ & Kamyon & Tır & Otobüs & $\begin{array}{c}\text { Ortalama } \\
\text { Taşıt Filosu }\end{array}$ \\
\hline 2,0 & 1,159 & 1,130 & 1,718 & 2,893 & 4,451 & 1,881 \\
\hline 4,0 & 1,171 & 1,145 & 1,766 & 2,996 & 4,543 & 1,913 \\
\hline 6,0 & 1,182 & 1,152 & 1,819 & 3,104 & 4,776 & 1,974 \\
\hline 8,0 & 1,227 & 1,168 & 1,851 & 3,096 & 5,209 & 2,093 \\
\hline 10,0 & 1,323 & 1,226 & 1,909 & 3,198 & 5,843 & 2,291 \\
\hline 12,0 & 1,447 & 1,311 & 1,991 & 3,385 & 6,609 & 2,537 \\
\hline 14,0 & 1,584 & 1,409 & 2,092 & 3,616 & 7,445 & 2,807 \\
\hline 16,0 & 1,728 & 1,513 & 2,206 & 3,870 & 8,315 & 3,091 \\
\hline 18,0 & 1,875 & 1,620 & 2,326 & 4,138 & 9,204 & 3,381 \\
\hline 20,0 & 2,023 & 1,725 & 2,447 & 4,408 & 10,096 & 3,673 \\
\hline
\end{tabular}

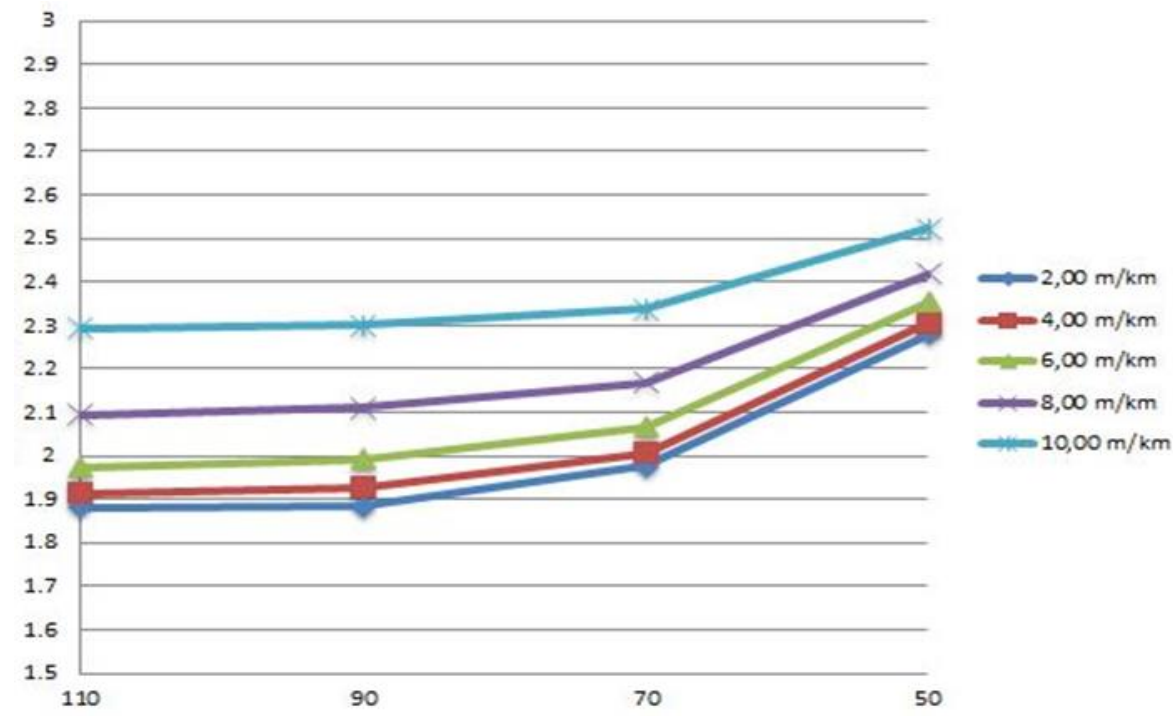

Şekil 6. Farklı hız ve pürüzlülük değerlerine göre yol kullanıcı maliyetleri

Şekil 6'da yol pürüzlülüğünün taşıt işletme maliyetine olan etkisi hedeflenen proje hızlarına göre incelenmiş olup yol pürüzlülüğünün artmasıyla ortalama taşıt filosunun yol kullanıcı maliyetlerinde artış meydana geldiği tespit edilmiştir.

Trafik hacmi, taşıt işletme hızlarına etki eden en büyük faktördür. Düşük hacim değerlerinde, taşıtların hızları da düşmektedir. Yoğun trafik hacminde taşıtların sürekli dur kalk yapması ya da düşük hızlarda seyir halinde olması taşıt işletme maliyetini arttırmaktadır. Ayrıca 
trafik esnasında beklenen süre kaybedilen zaman olarak kullanıcıya zaman kaybı maliyeti olarak yansımaktadır. Tablo 9'da taşıt türlerinin YOGT değeri artışıyla birlikte değişen kullanıcı maliyetleri görülmektedir.

Tablo 9. Farklı YOGT değerlerinde birim maliyetler (HDM-4) (TL/taşıt-km)

\begin{tabular}{|c|c|c|c|c|c|c|}
\hline $\begin{array}{c}\text { Günlük Trafik } \\
\text { (YOGT) }\end{array}$ & Otomobil & $\begin{array}{c}\text { Orta Yüklü } \\
\text { Ticari Taşıt }\end{array}$ & Kamyon & Tır & Otobüs & $\begin{array}{c}\text { Ortalama } \\
\text { Taşıt Filosu }\end{array}$ \\
\hline 5 & 1,159 & 1,130 & 1,718 & 2,893 & 4,451 & 1,881 \\
\hline 20 & 1,159 & 1,130 & 1,718 & 2,893 & 4,451 & 1,881 \\
\hline 65 & 1,159 & 1,130 & 1,718 & 2,893 & 4,451 & 1,881 \\
\hline 200 & 1,159 & 1,130 & 1,718 & 2,893 & 4,451 & 1,881 \\
\hline 650 & 1,159 & 1,130 & 1,718 & 2,893 & 4,451 & 1,881 \\
\hline 2000 & 1,159 & 1,129 & 1,717 & 2,891 & 4,453 & 1,881 \\
\hline 6500 & 1,152 & 1,106 & 1,693 & 2,834 & 4,539 & 1,890 \\
\hline 20000 & 2,633 & 1,892 & 2,198 & 3,817 & 13,833 & 4,793 \\
\hline 65000 & 2,633 & 1,892 & 2,198 & 3,817 & 13,833 & 4,793 \\
\hline
\end{tabular}

Genel olarak taşıt sürücüleri yatay kurplarda yavaşlama eğiliminde bulunurlar. Kurp boyunca meydana gelen hız değişimleri sürücünün davranışına, taşıta ve yol standartlarına bağlıdır. Ayrıca yatay kurpların yuvarlanma direnci üzerinde etkisi olduğundan dolayı taşıt işletme maliyetini belirlemede bu standartların belirlenmesi önemlidir. Düşey kurp tasarımında ise yüksek eğimler taşıtın daha yüksek performansta çalışmasını ve hız değişimlerine sebep olduğundan yakıt tüketimini arttırmaktadır.

Yol kullanıcı maliyetlerinin yol geometrisi değişimlerine göre analizi için yatay kurp ve düşey kurp girdileri tüm değerler minimize edilerek tekrardan hesap yapılmıştır. Yeni durumda, 1 yıllık maliyet 4.546.000 TL olarak hesaplanmıştır. Yolun geometrik analizi yapılmadan önceki maliyetini ise aynı bağıntı kullanılarak 5.873.000 TL olarak hesaplanmıştır. Geometrik standartların iyileştirilmesiyle işletme maliyetinde yaklaşı 1,5 milyon TL azalma gözlemlenmiştir.

\section{DEĞERLENDİRME VE SONUÇ}

Ülkemiz karayolu ağırlıklı, dengesiz bir ulaştırma sistemine sahiptir. İleride bu dengesizliği düzeltmek amacıyla planlar ve stratejiler belirlenmelidir. Bugün için ise, yapılacak en önemli çalışma, mevcut sistemin bilincinde olmak ve bu sistem içinde maliyetleri en aza indirebilme gayretini göstermektir. Bu da ancak sistemi kullanırken karşılanacak maliyetleri bilmekten geçmektedir. Bu da bunun gerekliliğine inanmak, hukuki ve mühendislik bağlamında sıkı tedbirler almak insan faktörünü de bu amaçtan haberdar etmekten geçmektedir. 
Dolayısıyla, ülkemiz açısından karayolu maliyetlerinin analiz edilmesi ve azaltılmasına yönelik çalışmalar önem arz etmektedir. Bu çalışma kapsamında; karayolu işletme maliyetleri incelenerek, bunları etkileyen faktörler örnek proje üzerinde değerlendirilmiştir. Buna göre; ağır taşıtların yakıt tüketimi, dolayısıyla taşıt işletme maliyetlerinin daha fazla olduğu gözlemlenmiştir. En fazla miktarda salınımı CO2 bileşeninin yaptığı ve diğer bileşenlerin ise göz ardı edilecek kadar az miktarda salınım yaptıkları tespit edilmiştir. Yol pürüzlülügüü taşıt hızına olumsuz olarak etki eden bir faktördür. Dolayısıyla, yol pürüzlülüğü arttıkça işletme maliyetleri artmaktadır. YOGT değerlerinin artması taşıt işletme maliyetlerini arttırmaktadır. Geometrik standartların iyileştirilmesi, karayolu işletme maliyetlerini önemli ölçüde azaltmaktadir.

Karayolu işletme maliyetleri açısından bakıldığında, mevcut ulaştırma altyapısının bakımı ve onarımının düzenli ve zamanında yapılması ülkemiz açısından önem arz etmektedir. $\mathrm{Bu}$ nedenle, ülkemizde ulaştırma altyapı yönetim sistemi kurulması çalışmaları başlatılarak, bakım ve onarım için gerekli olan gerçekçi bütçenin belirlenmesi gerekmektedir. Mevcut ulaştırma altyapısının yeterli seviyede korunması sonucu taşıt işletme maliyetlerinin en aza indirgenebilmesi beklenmektedir.

Sonuç olarak, bu çalışmada kaplama pürüzlülüğü, işletme hızı ve geometrik standartlara bağlı olarak karayolu işletme maliyetlerinin değişimleri incelenmiştir. Bu etkiler, düşük trafik hacmine sahip yol örneğinde değerlendirilirken, özellikle trafik hacminin yüksek olduğu yollarda geometrik standartların ve kaplama koşullarının iyileştirilmesiyle yol kullanıcı maliyetlerinde ciddi tasarrufların elde edilmesi kaçınılmazdır. Yol geometrik standartlarının iyileştirilmesiyle taşıt filosunun yol kullanıcı maliyeti 1,882 TL/taşıt-km'den 1,822 TL/taşıtkm'ye azalmıştır. Hızın artmasıyla taşıt işletme maliyetinde artış, zaman kaybı maliyetinde ise azalma gözlemlenmiştir. Taşıt işletme maliyeti 0,93 TL/taşıt-km, zaman kaybı maliyeti 0,69 TL/taşıt-km, emisyon maliyeti $0,01 \mathrm{TL} /$ taşıt-km ve yol güvenliği maliyeti $0,18 \mathrm{TL} /$ taşıt-km hesaplanmıştır. Yol geometrik standartlarının iyileştirilmeden önceki durumla karşılaştırıldığında, yol geometrik standartlarının değişiminin zaman kaybı maliyetine etkisinin en fazla olduğu tespit edilmiştir. 


\section{REFERENCES / KAYNAKLAR}

Bakırcı, E. (2005). Taşıt işletme maliyetleri bileşenlerinin irdelenmesi tasarruf bakışının yerleştirilmesi. 6. Ulaştırma Kongresi Bildiriler Kitabı, 395-404.

Burger, A. F. \& Gryp, A. V. D. (2008). Implementing hdm-4 version 2 for project level life cycle cost analysis. In Proceedings of 7th International Conference on Managing Pavement Assets, Alberta, Canada.

Das A., Bino, I. K. \& Pradeep, J. (2013). Road user effects model calibration in hdm4 - a case study. Proceedings of International Conference on Energy and Environment, Kottayam, India.

Karayolları Genel Müdürlüğü. (2014). Karayollarında hız. Ankara: Trafik Güvenliği Dairesi Başkanlığı Ulaşım Etütleri Şubesi Müdürlüğü.

Narwal, A. (2016). Review on vehicular emission models (hdm4). International Journal of All Research Education and Scientific Methods, 4(6), 44-49.

Ozbay, K., Jawad, D., Parker, N. \& Hussain, S. (2004). Life-cycle cost analysis: state of the practice versus state of the art. Transportation Research Record: Journal of the Transportation Research Board, Transportation Research Board of the National Academies, Washington, D.C., 1864(1), 62-70.

Tranter, P. (2004). Effective speeds: Car costs are slowing us down. Canberra, Australian Greenhouse Office, Department of the Environment and Heritage, 1-18.

Türkiye İstatistik Kurumu (TÜİK). http://www.tuik.gov.tr/

Victoria Transport Policy Institute (2018). Transportation cost and benefit analysis II - travel time costs. Erişim Tarihi: 10 Eylül 2018, www.vtpi.org/tca/tca0502.pdf

Yüksekli, A. U. (2006). Trafik ve değişkenlerinin üstyapı maliyetlerine etkisinin ömür döngü maliyet analizi yöntemi ile incelenmesi (Yüksek Lisans Tezi). YTÜ, İstanbul.

Zaniewski, J. P., Butler, B. G., Cunningham, G. \& Machemehl, R. (1982). Vehicle operating costs, fuel consumption, and pavement type condition factors (Report No: FHWA-PL-82-001). United States: Federal Highway Administration. 